Article

\title{
Experimental Study of Filtration Materials Used in the Car Air Intake
}

\author{
Tadeusz Dziubak * and Sebastian Dominik Dziubak
}

Faculty of Mechanical Engineering, Military University of Technology, gen. Sylwestra Kaliskiego Street 2, 00-908 Warsaw, Poland; sebastian.dziubak@wat.edu.pl

* Correspondence: tadeusz.dziubak@wat.edu.pl

Received: 8 July 2020; Accepted: 4 August 2020; Published: 7 August 2020

\begin{abstract}
Traditional cellulose filter media used for air filtration in vehicle engines are characterized by $99.9 \%$ filtration efficiency and accuracy above $2-5 \mu \mathrm{m}$. The highest engine component wear is caused by dust grains above $1 \mu \mathrm{m}$. Filter media with nanofiber additions provide greater filtration efficiency of dust grains below $5 \mu \mathrm{m}$. Filter material selection for vehicle engine air filter is a problem because their manufacturers mainly provide only the structure parameters: pore size, air permeability, and thickness. There is no information about material filtration properties using polydisperse test dust. The manuscript presents methodology and experimental test results of five samples A, B, C, D and $\mathrm{E}$, filter materials differing in their chemical composition and structure parameters. In the first stage, efficiency characteristics $\varphi_{w}$, filtration accuracy $d_{z \max }$ and the flow resistance $\Delta p_{w}$ depending on the dust absorption coefficient $k_{m}$ of three filter cartridges of each material, A, B, C, D and E, were determined. Then, from each material characteristics of one piece was selected in order to compare their initial and initial period efficiencies as well as changes in the flow resistance depending on the dust absorption coefficient $k_{m}$. Obtained results showed that the filter materials differ significantly in efficiency and accuracy values in the initial filtration period. Initial period duration is also different, i.e., filtration efficiency increasing time to a certain value, which for materials with a nanofiber layer is much shorter, which minimizes engine component wear. For materials with nanofibers, flow resistance increase intensity is greater, which results from surface filtration. Filtration efficiency of each filter material sample A, B, C, D and E was assessed with the filtration quality coefficient including the efficiency and flow resistance. In the available literature, the problem of increasing filtration efficiency in the initial period is known, but there are no results for specific filter materials. Research shows that filter material characteristics are closely related. Each increase in efficiency and accuracy of intake air filtration reduces engine components wear, but it is related to flow resistance increase in the engine intake system, which reduces its power, and increases need for more frequent filter servicing.
\end{abstract}

Keywords: filter medium; engine; particle size; nanofibers; separation efficiency; filtration performance; pressure drop; dust mass loading

\section{Introduction}

Road surfaces are a place of particle deposition from many different sources. First and foremost, it is mineral dust blown by the wind from the soil surrounding the road, from the sand and desert areas that cover about one third of the earth's surface [1]. Those include dust generated during field works, road works or construction works. The particles may include salt used for de-icing, plant matter, pollen, animal hair, and other biological matter from the surrounding areas [2]. Apart from the natural processes, significant amount of dust particles is formed as a result of human activities, including agriculture, industrial production and mining [3]. Contamination from anthropogenic 
sources include the particles released to the atmosphere as a result of processes between brake and coupling components [4-6] and tire contact with the road [7-9]. Those include particles from the engine's exhaust gases including soot, and engine components' wear products.

The main component of particles settled on the road is mineral dust, containing solids formed as a result of material processing, including crushing, milling, hammering, reloading, detonation and destruction of organic and inorganic matter, including rock, ore and metal. The friction created by the tire of a moving vehicle on the unpaved and dusty paved road or by the wind, lift the particles from the road surface and moves them around as the road dust $[10,11]$. The main component of the road dust is silica $\left(\mathrm{SiO}_{2}\right)$ - between $60-95 \%$. The other components (4-19\%) include different metal oxides: $\mathrm{Al}_{2} \mathrm{O}_{3}, \mathrm{~F}_{2} \mathrm{O}_{3}, \mathrm{CaO}, \mathrm{MgO}$ and organic matter [12,13].

The air from the atmosphere is the basic working medium of all internal combustion engines used in motor vehicles. The combustion of $1 \mathrm{~kg}$ of petrol requires at least $14.5 \mathrm{~kg}$ of air. During operation in nominal conditions, the internal combustion engine in passenger car requires $150-400 \mathrm{~m}^{3} / \mathrm{h}$ of air and, in trucks, $900-1400 \mathrm{~m}^{3} / \mathrm{h}$. The Leopard 2 tank engine requires over $6000 \mathrm{~m}^{3} / \mathrm{h}$ of air.

The internal combustion engines suck large amount of particles with the air. These are impurities with grain sizes not exceeding $\mathrm{dz}=80-100 \mu \mathrm{m}$. A characteristic feature of polluted air is the concentration of dust in the air $s\left(\mathrm{~g} / \mathrm{m}^{3}\right)$. It has different values depending on the conditions and the ground on which the vehicle is traveling. The lowest dust concentration in the air $\left(\mathrm{s}=2-20 \mathrm{mg} / \mathrm{m}^{3}\right)$ occurs on paved streets and roads, and the highest (up to $10 \mathrm{~g} / \mathrm{m}^{3}$ ) occurs when tracked vehicles are driven on training grounds with dry ground [12].

The most dangerous air contaminant for machinery is the mineral dust with high silica $\left(\mathrm{SiO}_{2}\right)$ content and a hardness of 7 on the Mohs scale. Silica is the main cause of high engine component wear including piston rings, cylinder sleeves, crankshaft main bearing journals and sleeves, valves and valve guides [14]. A minimum service life of those components determines engine life.

In turbine engines, there are no reciprocating components or slide bearings. High air flow rates $150-250 \mathrm{~m} / \mathrm{s}$, high exhaust gas rates (over $300 \mathrm{~m} / \mathrm{s}$ ) and high tangential velocity (200-500 m/s) allow large dust particles to achieve high kinetic energy at the point of contact with the compressor rotor blades, and may cause severe impact. The impact may cause premature erosion wear due to removal of metal microparticles from the component's surfaces, damage the surface structure and change its shape. As a result, engine efficiency and durability may be affected.

Smaller dust particles accumulate on the compressor body walls, particularly in the corners and on the guide vanes. Some dust particles with a significantly lower melting point (Sodium Chloride $\mathrm{NaCl}-1074 \mathrm{~K}$, Albite $\left.\mathrm{NaAlSi}_{3} \mathrm{O}_{8}-1388 \mathrm{~K}\right)$ compared to the average combustion temperature $(1600 \mathrm{~K})$ are melted in the combustion chamber; however, their inertia is sufficient to let them accumulate on the duct or rotor surface. The rate at which the dust layer accumulates, chemical composition of vitreous material (lime-magnesium-aluminosilicate deposits on the turbine guide vanes), and the erosion of compressor blades can reduce the mass flow rate through the engine and affect its performance: reduced power and increased fuel consumption, and as a result affect the flight safety [15].

Tests showed that the engine durability depends on the purity of inlet air [16-18]. The wear of engine components is caused by $1-40-\mu \mathrm{m}$ dust particles; however, the most damage is done by 5-20- $\mu$ m particles [19-24].

Excessive wear of piston rings and cylinder sleeves results in reduced compression pressure and engine power, and may increase the blow-by to the crankcase [25-27]. Some impurities (approx. 30\%) supplied with the air to the engine cylinders are removed with the exhaust gases, increasing PM emission by the engine [28].

Inlet air filtration systems in modern passenger car engines use single-stage filters with panel filters made of pleated filter paper. Trucks, heavy vehicles and other vehicles operated in high-dust concentration conditions are usually equipped with two-stage filtration systems [29-31].

The first stage is an inertial filter, a multi-cyclone or a mono-cyclone with vortex wheel, and the second filtration stage is a cylindrical porous panel filter made of pleated filter paper. 
A predominant filter medium used in the inlet air filters in modern combustion engines are filter papers (porous material), characterized by separation efficiency $d_{z} \geq 5 \mu \mathrm{m}$, filtration performance of $\varphi_{w}=99.9 \%$, low thickness $g_{m}=0.4-0.8 \mathrm{~mm}$, and small $\left(k_{\mathrm{m}}=200-250 \mathrm{~g} / \mathrm{m}^{2}\right)$ dust mass loading limited by a permissible pressure drop $\Delta p_{f d o p}$ of the air filter $[32,33]$. Filter paper retains dust particles at the fibers of a porous filter media as a result of different forces and separation mechanisms [34,35].

The inertial filter is characterized by the ability to separate large masses of dust from large air streams with an separation efficiency of 85-95\% and not very high filtration performance (over 15-35 $\mu \mathrm{m}$ ) without changing its flow resistance and the need for maintenance. Thus, a much smaller mass of dust gets on the paper element, which results in an extended service life of the air filter $[18,20,21]$.

Over time, the dust particles settle deep into the fibrous structure of the filter media, preventing air flow, resulting in pressure drop (increase in flow resistance $\Delta p_{f}$ ). It increases the additional costs of energy used to force the air to flow and reduce the filling ratio and engine power.

Cellulose filter media commonly used in inlet air filters in motor vehicles are made of fibers with relatively large diameters, usually over 10 microns. Many researchers show that reducing the fiber diameter in the filter bed increases the separation efficiency. Using 1-instead of $50-\mu \mathrm{m}$ fibers increases the separation efficiency 2000 times [36].

Separation efficiency mechanisms are not affected by the particle velocity at the inlet but by the relationship between the particle and fiber size and increases with an increase in particle size and a decrease in fiber diameter.

This phenomenon can be implemented by using polymer nanofibers, i.e., fibers with a diameter below $1 \mu \mathrm{m}$. A thin layer of nanofibers applied from the inlet side on a standard filter medium (e.g., cellulose) will retain the particles before reaching the inside of the filter medium. The dust retained at the surface of the nanofiber layer can be easily removed (filter cleaning) with an impulse of compressed air in the opposite direction to the air flow during normal operation. If the dust particles are accumulated on the surface of the filter medium, removing them under high pressure will not cause damage to the structure of the filter element.

Compared to the standard fibers, nanofibers show unique and new properties, for example, high surface area and significantly higher strength relative to their mass and higher chemical activity and moisture sorption. The term "nanofibers" is used for fibers manufactured using an "electrospinning" technology [37-44]. Nanofibers with very small diameters, approx. 50-800 nm, are used in the automotive industry. The manufacturers of filter media using nanofibers have developed proprietary technologies, e.g., Ultra-Web ${ }^{\circledR}$ and Fibra-Web ${ }^{\circledR}$ by Donaldson Company Inc. Minneapolis, MN, USA Finetex Mats ${ }^{\mathrm{TM}}$ by Finetex Technology Inc., USA and AMSOIL Ea Air Filters, USA and Canada [45].

Due to the limited mechanical and strength properties of the thin nanofiber layer (1 to $5 \mu \mathrm{m})$, it is applied on the surface made of a standard filter media with higher thickness and strength. The nanofibers can be arranged on one or both sides of the filter medium (cellulose, nylon or polyester). Using nanofibers as an additional layer on the filter media for air filters used in motor vehicles significantly increases the separation efficiency and filtration performance.

The designs of inlet air filters used in motor vehicle engines (Abrams M1 tank) using a filter element with added nanofibers and automatic pulse jet cleaning system PJCA (Pulse Jet Air Cleaner) are known from the literature $[14,45]$. This solution extends filter service life several times, and thus the time between filter replacements. PJAC system allows the filter to operate normally until the pressure drop at the filter exceeds a permissible value. After reaching a specific pressure drop, a pressure modulator is activated for 0.1 to $0.35 \mathrm{~s}$ to generate a compressed air pulse (0.4 to $0.6 \mathrm{MPa})$. The compressed air flowing in the opposite direction to the direction of air in the filtration process, removes the dust particles from the filter element surface; the dust particles are further removed to the dust collector [27,45].

Filter media of the cellulose type, made of relatively large fibers with a diameter in the range of 10-15 $\mu \mathrm{m}$, which ensure air filtration accuracy above $2-5 \mu \mathrm{m}$, are commonly used for filtering the engine inlet air. As all dust grains above $1 \mu \mathrm{m}$ wear the engine components, there is a need to improve 
the filtration efficiency of the engine intake air. The use of ultrafine fibers (less than $1 \mu \mathrm{m}$ ) has become the subject of interest in academic research and in industry, for example [14,46-51].

The authors of the work [14] presented an innovative filtering material made of sub-microfiber, which provides protection of engines against dust. A sub-microfiber substrate was prepared on a two-ply paper machine and its dust loading performance was compared with other filter materials in laboratory and field tests. The pressure drop of the used standard heavy duty (HD) filter after $1000 \mathrm{~km}$ of mileage and at a nominal flow rate of $1500 \mathrm{~m}^{3} / \mathrm{h}$ was over $2 \mathrm{kPa}$, which is the end of service life. Under the same conditions, the wet-folded submicrofiber filter achieved a pressure drop of more than $1 \mathrm{kPa}$, i.e., approximately $45 \%$ lower, demonstrating the advantages of the new filter material in the field test. In laboratory testing, when the pressure drop of a standard heavy duty medium reached $2 \mathrm{kPa}$, the pressure drop of the wet-laid submicrofiber material in the same bed of the dust mass was $38 \%$ lower than that of the standard heavy-duty medium.

In the work [46], cellulose nanofibers were prepared using the Lyocell fiber nanofibrillation method with the use of a PFI refiner, and the influence of nanofibers in the filter bed on the filtration efficiency and flow resistance was investigated. The mass fraction of nanofibers in the filter bed was changed in the range of $0-20 \%$. With the increase in the proportion of nanofibers, the pressure drop increased. Upon reaching a share of $15 \%$, the pressure drop increased sharply. For particles ranging in size from 0.03 to $2 \mu \mathrm{m}$, the separation efficiency curves show a typical $\mathrm{V}$ shape. With the increase in the proportion of nanofibers, the separation efficiency assumed higher and higher values. The particle size at which the performance was lowest on the performance curve was that of the Most Penetrating Particles Sizes (MPPS). The MPPS for all five cases was approximately $200 \mathrm{~nm}$. The separation efficiency of MPPS increased from 0.1 to 0.6 , indicating that cellulose nanofiber made from Lyocell was effective in improving the separation efficiency of the filter paper.

The authors of the work [47] developed a modified melt-blown technology which allowed us to produce filters composed of micrometer as well as nanometer sized fibers. One conventional microfibrous filter and five nanofibrous filters were examined. The complete structural characteristics, pressure drop and separation efficiency of removal of aerosol particles with diameters $10-500 \mathrm{~nm}$ were determined for all media.

The results of the experiments confirmed that using nanofibrous filters a significant growth of separation efficiency for the MPPS range can be achieved and the pressure drop rises moderately. Simultaneously, we noticed a shift of the MPPS towards smaller particles. Consequently, the quality factor for bilayer systems composed of a microfibrous support and a nanofibrous facial layer was considerably higher than this one for a conventional microfibrous filter alone.

Wang et al. [48] introduced novel hybrid filters of aligned carbon nanotube (CNT) sheets, sandwiched between electrospun polyimide (PI) nanofiber membranes serving as the supporting layers, were fabricated for the capture of fine particles. The CNT sheets and PI nanofiber membranes were thermally bonded together by melting electrospun polyetherimide (PEI) nanofibers. Two different kinds of filter structures were prepared, where multiple layers of aligned CNT sheets were either stacked together on top of each other or separated from each other by a PEI layer. The separation efficiency tests showed that the filtration efficiency increased with increasing number of CNT sheets. The maximum separation efficiency reached $99.99 \%$ at $0.053 \mathrm{~m} / \mathrm{s}$ face velocity for $0.3-\mu \mathrm{m}$ particles by the four-layer CNT filter, while the pressure drop was only $120 \mathrm{~Pa}$.

Pei et al. [49] presented the results of research on the characteristics of the inlet air filter material covered with nanofibers obtained with the use of potassium chloride, ammonium sulfate, and ammonium nitrate particles in both dry and wet states. The performance was compared to that of conventional cellulosic filter media using 4 inches of water under various test conditions. The research was aimed at examining the effect of relative humidity and hygroscopic salt particles on the performance of an air filter covered with nanofibers. Switching from a conventional cellulose filter material to a nano-coated filter material can improve filter life by a factor of three or more depending on the material 
used in this test. However, when the particles are wet, the nanofiber layer reduces the volumetric load to about $50 \%$ based on the media used in this test.

Liu et al. [50] investigated the relationship between filtration efficiency, inlet velocity, and particle size of a PTFE-coated filter medium. The results of tests of three filters covered with a polytetrafluoroethylene (PTFE) membrane are presented. A number of experiments were carried out on filter performance and related parameters such as particle size and frontal velocity. In the experiments, $0.1 \% \mathrm{NaCl}$ solution particles with sizes $10,20,50,100,200$ and $300 \mathrm{~nm}$ were used. The average particle size was about $50 \mathrm{~nm}$. The separation efficiency tests were carried out at inlet velocities of $0.003,0.01$, $0.053,0.1$ and $0.15 \mathrm{~m} / \mathrm{s}$. For particles from 10 to $300 \mathrm{~nm}$, the separation efficiency curves show a typical $\mathrm{V}$ shape. The lowest point of the V-shaped curve is the minimum efficiency and corresponds to the Most Penetrating Particles Sizes (MPPS). At $0.053 \mathrm{~m} / \mathrm{s}$, for Filters A, B and C, the minimum separation efficiencies are $99.800 \%, 99.997 \%$ and $99.993 \%$, respectively, and the MPPS values are 100, 70 and $100 \mathrm{~nm}$, respectively. Membranefilters with larger pore sizes allow more penetration of large particles.

Liu et al. [51] presented studies that aimed to determine the effect of pore size and fiber diameter on the performance of ultra-low emission bag filters. In this study, three kinds of conventional polyester filter (depth filtration media) and two kinds of polytetrafluoroethylene membrane-coated polyester filter (surface filtration media), having various filter pore sizes and fiber diameters, were tested to determine the performance of static and dynamic filtration. In the dynamic filtration performance experiments, $50 \%$ of the test dust was less than $2.5 \mu \mathrm{m}$ in size, and the mass mean aerodynamic diameter of the dust was $1.5 \mu \mathrm{m}$. The filtration velocity was $2 \mathrm{~m} / \mathrm{min}(0.033 \mathrm{~m} / \mathrm{s})$, and the dust concentration was $s=18.4 \mathrm{~g} / \mathrm{m}^{3}$. In the depth filtration media, the separation efficiency and the pressure drop of the fabric structure were improved when the filter pore size and the fiber diameter were smaller in magnitude.

The filter media must be evaluated for separation efficiency, filtration performance and changes in pressure drop. The manufacturers of filter media often specify the structural parameters (pore size, air permeability, thickness) without giving any information on the filtration performance for a test dust. This data can be obtained by experimental tests on filter medium specimens that are costly and time consuming; however, those test methods are the most reliable. The study presents methods and test results for standard filter media (cellulose and polyester) and standard filter media with a nanofiber layer and PTFE membrane. The results can be used to choose the most suitable filter medium for the inlet air of a motor vehicle's engine to minimize the engine wear and extend its mileage.

\section{Authors' Own Research}

Filter material experimental tests included organization, research and results analysis. In the organizational part, a test stand and particle counter were prepared, and test conditions were adopted: dust concentration, $Q_{w}$ stream range, filtration speed, and measurement duration cycle. A research methodology was developed. Filter material samples (filter cartridges) were selected for testing and they were marked as A, B, C, D and E. Filter materials data were summarized in the table.

The research part was carried out in two stages, with the following courses:

- Flow characteristics $\Delta p_{w}=f\left(Q_{w}\right)$ of selected filter materials (cartridges) were made by making five repetitions for each $Q_{w}$ value.

- Efficiency $\varphi_{w}$, filtration accuracy $d_{z \max }$ and flow resistance $\Delta p_{w}$ characteristics depending on dust absorption coefficient $k_{m}$ of three filter cartridges of each material, A, B, C, D and E, were made.

Measurement result analysis was performed in the scope of:

- From each material, A, B, C, D and E, one of the sample characteristics were selected in order to compare (on one graph) their initial efficiencies and duration of the initial period, as well as changes in flow resistance depending on dust absorption coefficient $k_{m}$.

- On the example of cartridge A (cellulose), changes in the number of dust grains in the air behind the filter cartridges in successive measuring intervals and after subsequent test cycles are presented. 
- On the example of filter cartridge $\mathrm{A}$ and $\mathrm{E}$, the particle size distribution of grains in the exhaust air was analyzed after measurement No. 1 and after measurement corresponding to the end of the initial filtration period.

- Using the quality factor $q$, the filtration properties of the tested material samples were assessed.

Results analysis was completed with a summary in the form of conclusions.

\subsection{Purpose, Scope and Subject of Tests}

The tests aimed to determine and compare the filtration parameters including separation efficiency, filtration performance and pressure drop at the filter elements made of different filter media (cellulose, polyester, cellulose and polyester, cellulose and polyester with nanofiber layer, polyester with PTFE membrane) by determining the following filtration characteristics:

- $\quad$ Filtration performance $d_{z \max }=f\left(k_{m}\right)$;

- $\quad$ Separation efficiency $\varphi_{w}=f\left(k_{m}\right)$;

- $\quad$ Pressure drop $\Delta p_{w}=f\left(k_{m}\right)$;

- $\quad$ Flow (aerodynamic) characteristics $\Delta p_{w}=f\left(Q_{w}\right)$;

where $Q_{w}\left(\mathrm{~m}^{3} / \mathrm{h}\right)$ is the air volume flow rate through the filter element, $k_{m}$ is the mass loading of dust $m_{z}$ retained and evenly distributed over $1 \mathrm{~m}^{2}$ of the active filter media surface area, expressed as:

$$
k_{m}=\frac{m_{z}}{A_{w}}\left(\frac{\mathrm{g}}{\mathrm{m}^{2}}\right) .
$$

The filtration rate is defined as a product of air volume flow rate through the filter element $Q_{w \max }$, equal to the engine air demand at maximum power $n_{N}$ and the active surface area of the filter paper $A_{w}$ based on the following relationship:

$$
v_{F w}=\frac{Q_{w}}{A_{w} \times 3600}(\mathrm{~m} / \mathrm{s}) .
$$

The tests covered the filter elements (Figure 1 ) of the same type, with identical dimensions and filtration surface area $A_{w}=0.1534 \mathrm{~m}^{2}$ made of different filter media. To facilitate the result analysis, the filter media (elements) has been assigned a letter designation, A, B, C, D and E.

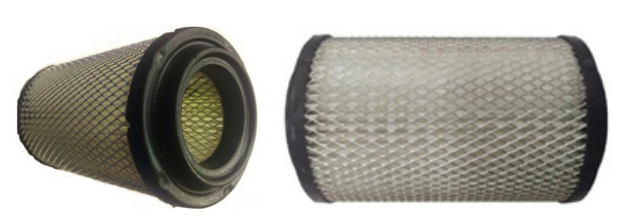

Figure 1. Filter element.

Table 1 shows characteristic parameters of the tested filter media. A nanofiber layer is applied on the inlet side of the filter media D (cellulose+polyester). A microporous PTFE membrane is applied on the inlet side of the filter media $\mathrm{E}$ (polyester). The filter media $\mathrm{E}$ shows 10 times lower air permeability compared to the filter media A and is 2 times lower compared to the other tested filter media.

Table 1. The parameters of the tested filter media based on the data provided by the manufacturer.

\begin{tabular}{cccccc}
\hline \multirow{2}{*}{ Parameters } & \multicolumn{5}{c}{ Filter Medium Identification } \\
\cline { 2 - 6 } Filter medium & A & B & C & D & E \\
\hline Permeability $q_{p}\left(\mathrm{~m}^{3} / \mathrm{m}^{2} / \mathrm{h}\right)$ at $200 \mathrm{~Pa}$ & 3015 & 540 & 685 & $\begin{array}{c}\text { Polyester + } \\
\text { membrane PTFE }\end{array}$ \\
\hline Basis weight $g_{m}\left(\mathrm{~g} / \mathrm{m}^{2}\right)$ & 121 & 180 & 135 & 130 & 288 \\
\hline Thickness $g_{z}(\mu \mathrm{m})$ & 610 & 550 & 360 & 300 & 260 \\
\hline
\end{tabular}




\subsection{Test Methods and Conditions}

Tests were carried out on a test stand (Figure 2) with a Pamas 2132 particle counter with HCB-LD-2A-2000-1 sensor. The particle counter records the number and size of dust particles in the air $Q_{w}$ downstream of the filter element from 0.7 to $100 \mu \mathrm{m}$ at $i=32$ intervals by diameter $\left(d_{\text {zimin }}-d_{\text {zimax }}\right)$.

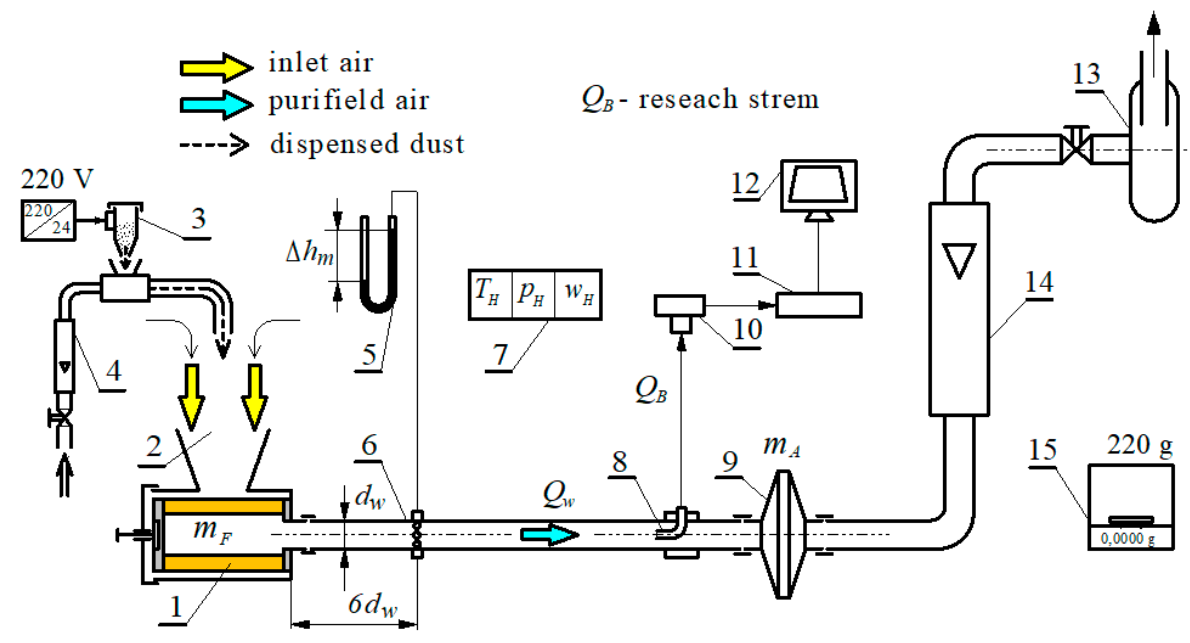

Figure 2. Diagram of the filter element test stand: 1-filter element, 2-dust chamber, 3-dust dispenser, 4-rotameter, 5-U-tube manometer, 6-measuring tube, 7-humidity, ambient air temperature and pressure measurement unit, 8-measuring probe, 9-absolute filter, 10-sensor, 11—particle counter, 12-measuring computer, 13-suction fan, 14-rotameter, 15-analytical balance.

At a specific distance downstream of the filter, a tip of the measuring probe is installed centrally in the axis of the measuring line supplying the air to the particle counter. A special filter protecting the rotameter is installed at the measuring line. A PTC-D test dust, an equivalent of AC-fine test dust was used. Figure 3 shows chemical composition and particle size distribution of test dust [48]. The mass fraction of 0 - to $5-\mu \mathrm{m}$ particles in the overall dust mass is nearly $40 \%$. Due to its small size, the dust particles are not easily retained by the porous filter media. Over $67 \%$ are $\mathrm{SiO}_{2}$ particles-a mineral showing high hardness (7 out of 10 on a Mohs scale), causing engine components wear.

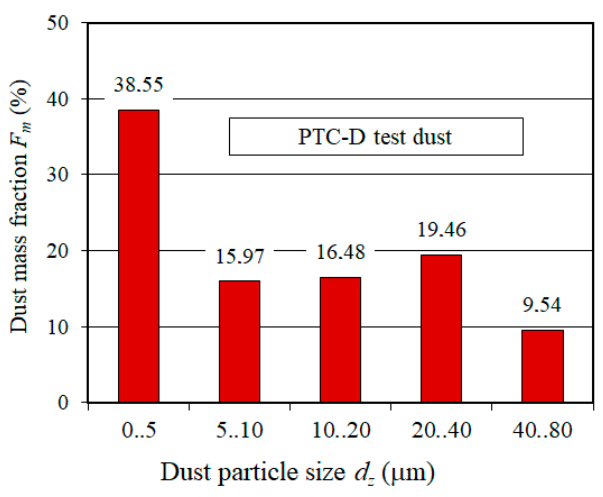

(a)

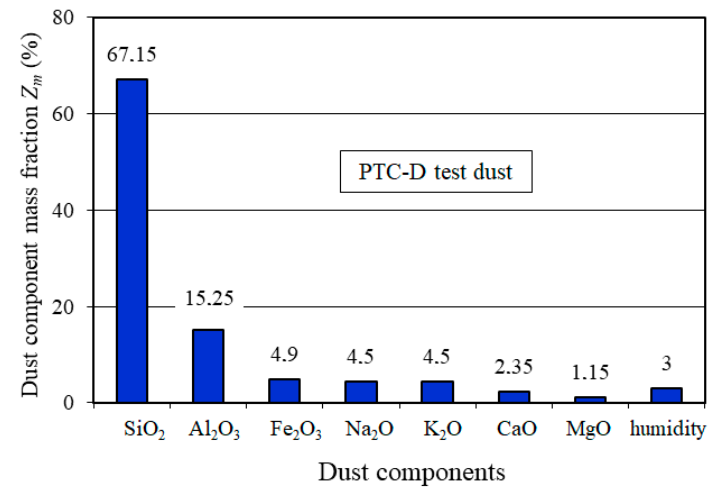

(b)

Figure 3. PTC-D test dust: (a) dust mass fraction, (b) dust component mass fraction [52].

Flow characteristics $\Delta p_{w}=f\left(Q_{w}\right)$ of the filter elements were determined at 8 points for the air volume flow rate $Q_{w}=Q_{w \text { min }}-Q_{w \max }$. The maximum air volume flow rate $Q_{w m a x}$ was determined for the maximum filtration rate $v_{F w}=0.1 \mathrm{~m} / \mathrm{s}$. For passenger car filters, the maximum filtration rate of the filter paper is between $v_{F w}=0.07$ to $0.12 \mathrm{~m} / \mathrm{s}[18,20,53-56]$. For the filtration rate of $\left(v_{F w}=0.1 \mathrm{~m} / \mathrm{s}\right)$, the maximum air volume flow rate calculated from the following relationship is $Q_{w m a x}=56 \mathrm{~m}^{3} / \mathrm{h}$. 


$$
Q_{w \max }=A_{w} \cdot v_{F w} \cdot 3600\left(\mathrm{~m}^{3} / \mathrm{h}\right)
$$

A RIN 60 type rotameter with a measuring range of 3 to $67 \mathrm{~m}^{3} / \mathrm{h}$ and accuracy class of 2.5 was used to measure the air volume flow rate $Q_{w}$.

Filtration characteristics of the filter elements: separation efficiency $\varphi_{w}=f\left(k_{m}\right)$, filtration performance $d_{z \max }=f\left(k_{m}\right)$ and pressure drop $\Delta p_{w}=f\left(k_{m}\right)$ were determined using a gravimetric method at a constant filtration rate $v_{F w}=0.1 \mathrm{~m} / \mathrm{s}$. Dust mass retained by the tested filter element and the absolute filter in subsequent $j$ cycles after time $\tau_{p}$ (evenly dosing time) to the filter was determined. Dust concentration at the filter element inlet was $s=0.5 \mathrm{~g} / \mathrm{m}^{3}$. The duration (uniform dust batching time) was $\tau_{p}=3 \mathrm{~min}$ in the initial period (I) and $\tau_{p}=9-12 \mathrm{~min}$ in the main period (II) of the filter working time. After each cycle $j$, the following parameters were determined for the filter element: separation efficiency, filtration performance, pressure drop and dust absorption coefficient. Dust mass retained by the filter element and the absolute filter was determined using an analytical balance with a 220-g capacity and a 0.1-mg readability.

During the measuring cycle, the particle counter was activated $60 \mathrm{~s}$ before the planned test end to count the number and size of dust particles in the air downstream of the filter.

Following points were determined after each measuring cycle $j$ :

Pressure drop $\Delta p_{w j}$ at the filter as a static pressure drop upstream and downstream of the filter based on the measured height $\Delta h_{m j}$ (after the dust supply ended) at a U-tube manometer using the following relationship:

$$
\Delta p_{w j}=\frac{\Delta h_{m j}}{1000} \cdot\left(\rho_{m}-\rho_{H}\right) \cdot g(\mathrm{~Pa}),
$$

where $\rho_{m}$ is the manometric liquid density $\left(\mathrm{kg} / \mathrm{m}^{3}\right), \rho_{H}$ is the air density $\left(\mathrm{kg} / \mathrm{m}^{3}\right), g$ is the gravitational acceleration $\left(\mathrm{m} / \mathrm{s}^{2}\right)$.

1. Separation efficiency, as a dust mass product $m_{Z F j}$ retained by the filter and dust mass $m_{D j}$ supplied to the filter during the next $j$ cycle based on the following relationship:

$$
\varphi_{j}=\frac{m_{F j}}{m_{D j}}=\frac{m_{F j}}{m_{F j}+m_{A j}} 100 \%
$$

2. Dust mass loading $k_{m j}$ of the tested filter medium:

$$
k_{m j}=\frac{\sum_{j=1}^{n} m_{F j}}{A_{w}}\left(\mathrm{~g} / \mathrm{m}^{2}\right) .
$$

3. Number of dust particles $N_{z i}$ in the air stream downstream of the filter (passing through the filter media) in the intervals by diameter $\left(d_{z i m i n}\right.$ to $\left.d_{z i m a x}\right)$.

4. Filtration performance as the largest dust particle size $d_{z j}=d_{z \max }$ in the air downstream of the filter.

5. Fraction of each dust particle size in the air downstream of the filter for each cycle:

$$
U_{z i}=\frac{N_{z i}}{N_{z}}=\frac{N_{z i}}{\sum_{i=1}^{32} N_{z i}} 100 \%
$$

where $N_{z}=\sum_{i=1}^{32} N_{z i}$ the total number of dust particles passing through the filter (for all measuring intervals) in the test cycle.

Test cycle used in the study involved five counts of dust particles from the range of 0.7 to $35 \mu \mathrm{m}$, divided into 32 intervals by diameter $\left(d_{z \min }\right.$ to $\left.d_{z \max }\right)$.

In accordance with the method, the following filtration characteristics were determined: separation efficiency $\varphi_{w}=f\left(k_{m}\right)$, filtration performance $d_{z \max }=f\left(k_{m}\right)$ and pressure drop $\Delta p_{w}=f\left(k_{m}\right)$ of the filter elements A, B, C, D and E. Three specimens of each filter element with the same filter medium were 
tested. The flow characteristics $\Delta p_{w}=f\left(Q_{w}\right)$ were determined before the filter element tests using the test dust.

\section{Test Result Analysis}

Figure 4 shows the test results of the flow characteristics $\Delta p_{w}=f\left(Q_{w}\right)$ of the tested filter elements. A parabolic increase in pressure drop $\Delta p_{w}=f\left(k_{m}\right)$ with an increase in air volume flow rate can be observed, corresponding to the data from the literature.

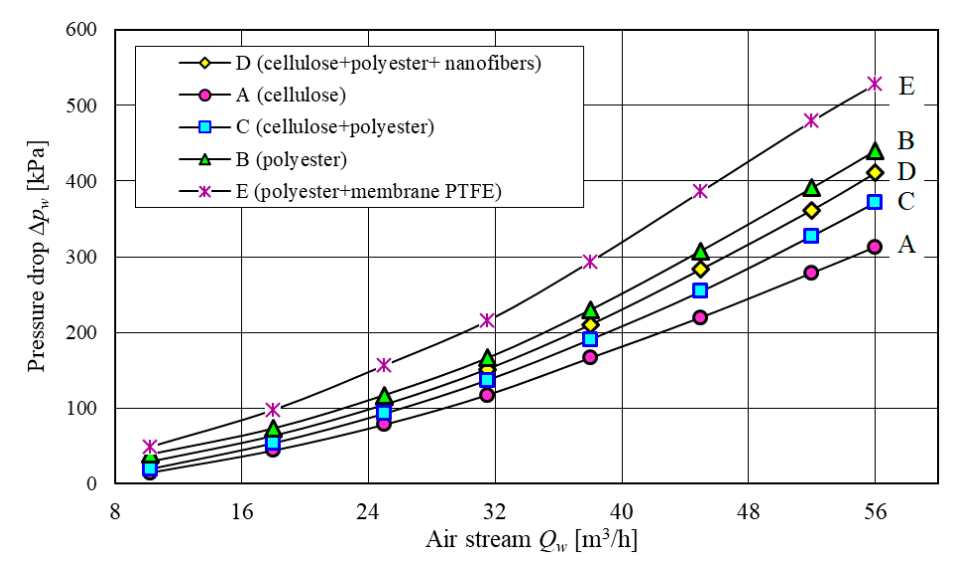

Figure 4. Flow characteristics $\Delta p_{w}=f\left(Q_{w}\right)$ of the tested filter elements.

The highest pressure drop in the entire tested air volume flow rate $Q_{w}$ range was observed for the filter element E-a filter bed made of polyester with PTFE membrane. For $Q_{w m a x}=56 \mathrm{~m}^{3} / \mathrm{h}$, the pressure drop at the filter element $\mathrm{E}$ is $\Delta p_{w}=528 \mathrm{~Pa}$ (Figure 4). It is over $20 \%$ more than the pressure drop at the polyester bed and over $70 \%$ more than the pressure drop at the filter medium A (cellulose). The filter medium A achieves the lowest pressure drop $\left(\Delta p_{w}=312 \mathrm{~Pa}\right)$ (Figure 4$)$, due to high permeability $\left(838 \mathrm{dm}^{3} / \mathrm{m}^{2} / \mathrm{s}\right)$, significantly higher than observed for other filter media. The pressure drop at the other filter media (C and D) is between 370 and $410 \mathrm{~Pa}$. The significantly higher pressure drop at the filter medium $\mathrm{E}$ compared to other filter media is due to a very low permeability of the filter bed $\left(80 \mathrm{dm}^{3} / \mathrm{m}^{2} / \mathrm{s}\right)$ - see Table 1 .

The example test results for the filtration characteristics including separation efficiency $\varphi_{w}=f\left(k_{m}\right)$, filtration performance $d_{z \max }=f\left(k_{m}\right)$ and pressure drop $\Delta p_{w}=f\left(k_{m}\right)$ of three specimens of filter elements $A$ and $D$ and three specimens of filter element $E$ are shown in Figure 5 (element A), Figure 6 (element D) and Figure 7 (element E).

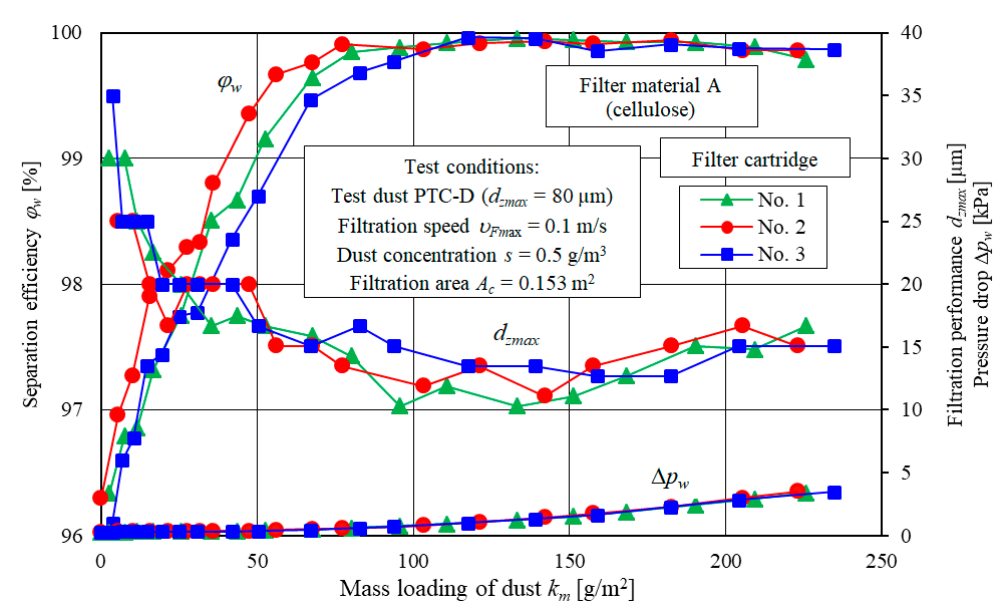

Figure 5. Separation efficiency $\varphi_{w}$, filtration performance $d_{z m a x}$ and pressure drop $\Delta p_{w}$ as a function of dust mass loading $k_{m}$ for three filter elements A specimens. 
The presented separation efficiency $\varphi_{w}$, filtration performance $d_{z m a x}$ and pressure drop $\Delta p_{w}$ of three filter element A specimens (Figure 5) differ slightly (form and value). The curve is similar and corresponds to the information provided by the authors of other research studies $[20,22,56]$. However, there are differences in the values of the initial filtration efficiency (for dust mass loading from 0 to $70 \mathrm{~g} / \mathrm{m}^{2}$ ) for three A filter cartridges (Figure 5). According to the authors, the different filtration efficiency values obtained at the initial stage result from the different structure of the same type of paper in individual cartridges. The active surface of the paper in each filter could also have been different (than assumed on the basis of the filter producer's data).

This had a direct impact on the effectiveness of the inertia and direct hooking mechanism, which are decisive in depth filtration in the bed. The authors assumed that all filter cartridges are similar which is related to their mass production. In particular, it was assumed that the filter material structure and its thickness in each filter cartridge is the same. It was also assumed that the active surface area of the cartridges is the same. With the same value of the air stream $Q$ during the tests, the filtration speed $v_{F w}$ should also be the same.

Similar curves can be observed for the filter elements D (Figure 6) and E (Figure 7). Significant differences in the form and values of curves for the filter element $\mathrm{A}, \mathrm{D}$ and $\mathrm{E}$ are due to the different filter media and different structural parameters.

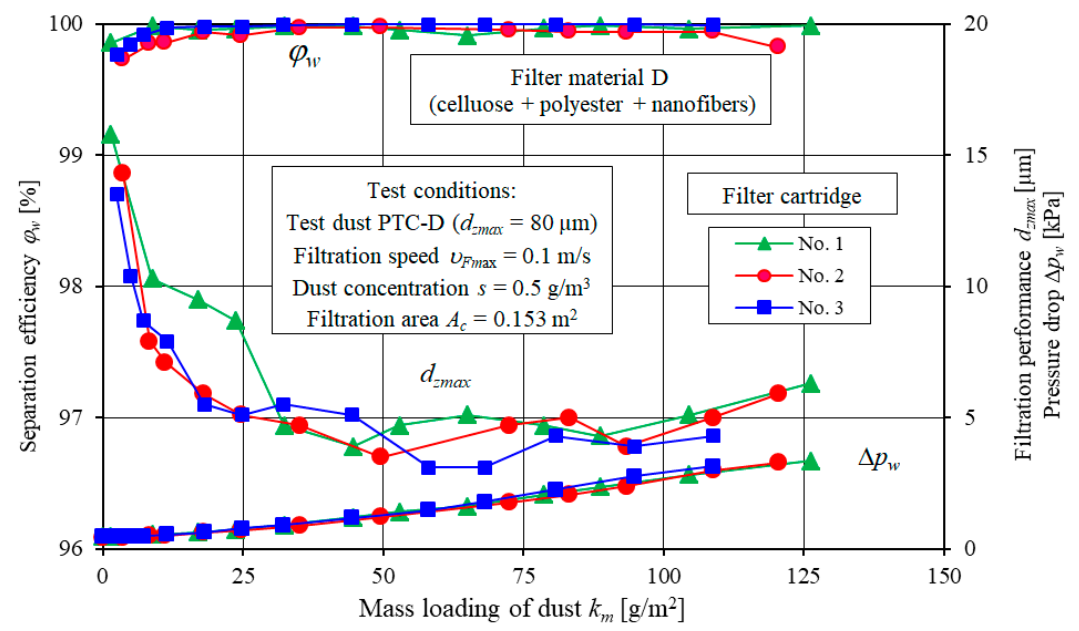

Figure 6. Separation efficiency $\varphi_{w}$, filtration performance $d_{z m a x}$ and pressure drop $\Delta p_{w}$ as a function of dust mass loading $k_{m}$ for three filter elements D specimens.

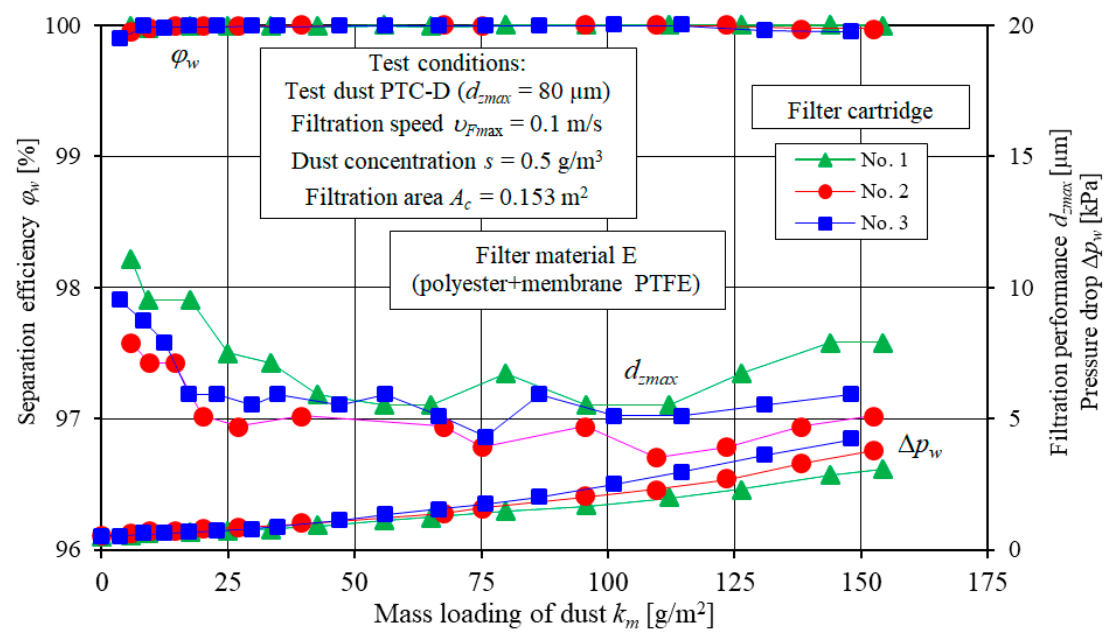

Figure 7. Separation efficiency $\varphi_{w}$, filtration performance $d_{z \max }$ and pressure drop $\Delta p_{w}$ as a function of dust mass loading $k_{m}$ for three filter elements E specimens. 
Figures 8 and 9 show separation efficiency $\varphi_{w}=f\left(k_{m}\right)$, filtration performance $d_{z \max }=f\left(k_{m}\right)$ and pressure drop $\Delta p_{w}=f\left(k_{m}\right)$ of the filter elements made of standard filter media: A (cellulose) and B (polyester). The characteristics were compared with the characteristics of the filter elements with a filter media being a composite of different layers: C (cellulose+polyester), D (cellulose+polyester+nanofibers), E (polyester+PTFE membrane).

Separation efficiency $\varphi_{w}$, filtration performance $d_{z m a x}$ and pressure drop $\Delta p_{w}$ of one out of three filter element A, B, C, D and E specimens were used in the analysis. The characteristics of five filter elements $\mathrm{A}, \mathrm{B}, \mathrm{C}, \mathrm{D}$ and $\mathrm{E}$ with different filter media have a similar form and significantly different values.

With an increase in dust mass retained by the filter layer (increase in $k_{m}$ factor), separation efficiency, filtration performance and pressure drop of the filter elements A, B, C, D and E increase, however, at a different rate and with different initial values. The characteristics are the result of the dust particles being retained by the fiber surface and filling the voids (pores). This phenomenon has been widely discussed in the literature $[20,22,38,41]$.

By convention, the operation of the tested filter elements can be divided into two stages. The first (I), initial stage of operation of each filter element lasts until the separation efficiency of $\varphi_{w}=99.9 \%$ is reached. This stage is characterized by a low initial separation efficiency, filtration performance and pressure drop.

Initial separation efficiencies of the tested filter elements vary. The lowest value $\left(\varphi_{w 0 A}=96.3 \%\right)$ was observed for the filter element made of filter medium A (cellulose). The elements B, C, D and E show higher initial separation efficiency: $\varphi_{w 0 B}=98 / 9 \%, \varphi_{w 0 C}=98.2 \%, \varphi_{w 0 D}=99.8 \%, \varphi_{w 0 E}=99.97 \%$, respectively (Figure 8).

With an increase in dust mass retained by the filtration layer (increase in $k_{m}$ factor), the separation efficiency of the tested filter elements increases. The required separation efficiency $\left(\varphi_{w}=99.9 \%\right.$ - end of stage I) is achieved by the filter elements working in similar conditions (the same dust concentration and air volume flow rate) at different times. Filter element $A$ reaches efficiency of $\varphi_{w}=99.9 \%$ at the mass loading of dust of $k_{m A}=110.7 \mathrm{~g} / \mathrm{m}^{2}$. For the elements B, C, D and E made of different filter media, the first stage is significantly shorter.

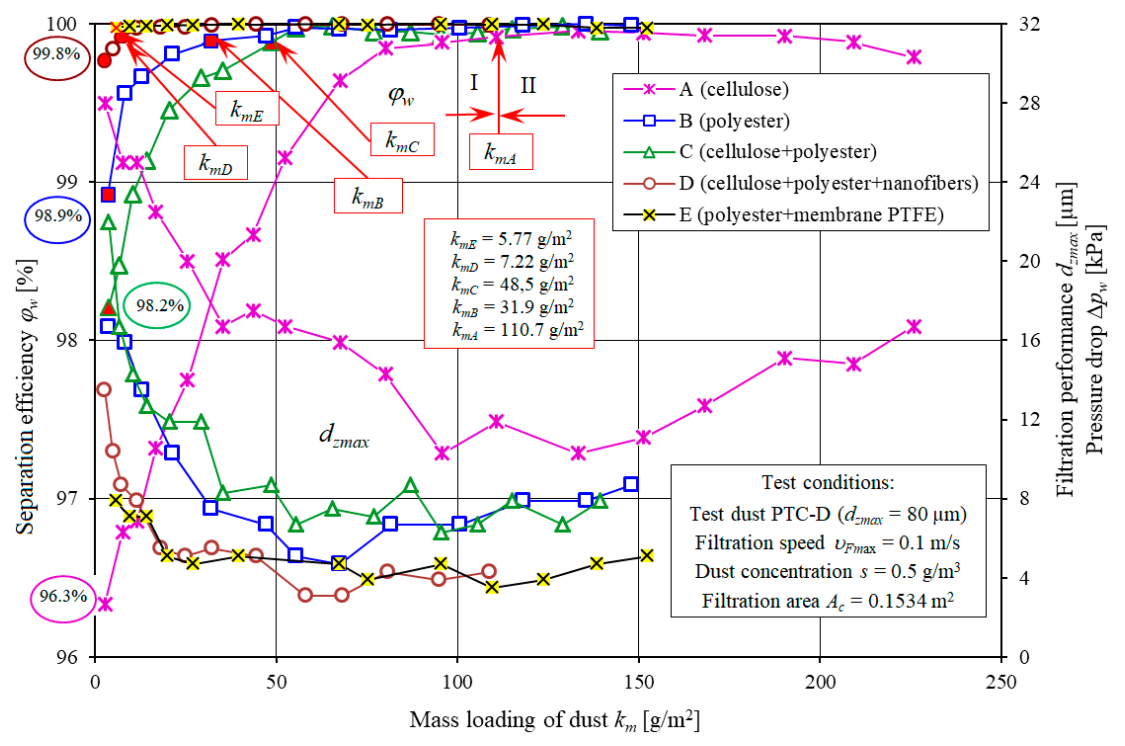

Figure 8. Separation efficiency $\varphi_{w}$ and filtration performance $d_{z m a x}$ as a function of dust mass loading $k_{m}$ of the tested filter elements.

For the filter element E (polyester+PTFE membrane) and the filter element D (cellulose+ polyester+nanofibers), stage I ends first after reaching the mass loading of dust of $k_{m E}=5.77 \mathrm{~g} / \mathrm{m}^{2}$ and $k_{m D}=7.22 \mathrm{~g} / \mathrm{m}^{2}$, respectively. For the filter element B (polyester), stage I ends at the mass loading of 
dust $k_{m B}=31.9 \mathrm{~g} / \mathrm{m}^{2}$, and for the filter element $\mathrm{C}$ (cellulose + polyester), at the mass loading of dust $k_{m C}=48.5 \mathrm{~g} / \mathrm{m}^{2}$ (Figure 7).

At the beginning of the filtration process, the maximum size of dust particles downstream of the filter (in the filtered air) may vary. The largest dust particles $\left(d_{z \max }=28 \mu \mathrm{m}\right)$ were observed downstream of the filter element $\mathrm{A}$ (cellulose), and the smallest $\left(d_{z \max }=7.9 \mu \mathrm{m}\right)$, downstream of the filter element $\mathrm{E}$ which is strictly correlated with the initial separation efficiency of the filter elements. This results from the higher basis weight and smaller pores of the tested filter media (Table 1).

With an increase in dust mass retained by the filter bed, the particles accumulate at the surface of the porous structure fibers and at the surface of previously accumulated particles, creating a constantly growing and complex dendritic structures (agglomerates), filling the voids between the fibers. The result of changes in the bed structure is an increase in separation efficiency. The size of the dust particles downstream of the filter decreases gradually. After I stage, the dust particles are between $d_{z \max }=10.3-11.9 \mu \mathrm{m}$ (filter element $\mathrm{A}$ ) and $d_{z \max }=3.1-5.5 \mu \mathrm{m}$ (filter element $\mathrm{D}$ and $\mathrm{E}$ ).

The initial stage of operation of filter element A made of cellulose is several times longer than observed for other filter elements. It significantly affects the durability of the engine. Low separation efficiency and filtration performance in the initial stage (after using a new filter element) results in the presence of large dust particles above $5 \mu \mathrm{m}$, significantly affecting the premature wear of engine components, mostly piston, piston rings and cylinder sleeves. The duration of the initial filtration stage may be reduced by using the filter medium with a layer of nanofibers or a PTFE membrane. High separation efficiency and filtration performance $99.9 \%$ is achieved by the filter elements much earlier than in filters made of standard filter media (cellulose) to eliminate the effect of air impurities on premature wear and durability of the engine.

The filtered air contains dust particles with different sizes and in different volumes. A predominant particle size is between 0.7 and $1.1 \mu \mathrm{m}$ (Figure 9). With an increase in dust particle size $d_{z}$ in the air downstream of the filter, the number of particles $N_{p}$ is reduced, indicating the increasing separation efficiency of the tested filter medium. In the last interval, a single dust particle is usually present $\left(d_{z}=d_{z \max }\right.$ maximum size) (Figure 9$)$ that is used as a measure of filtration performance.

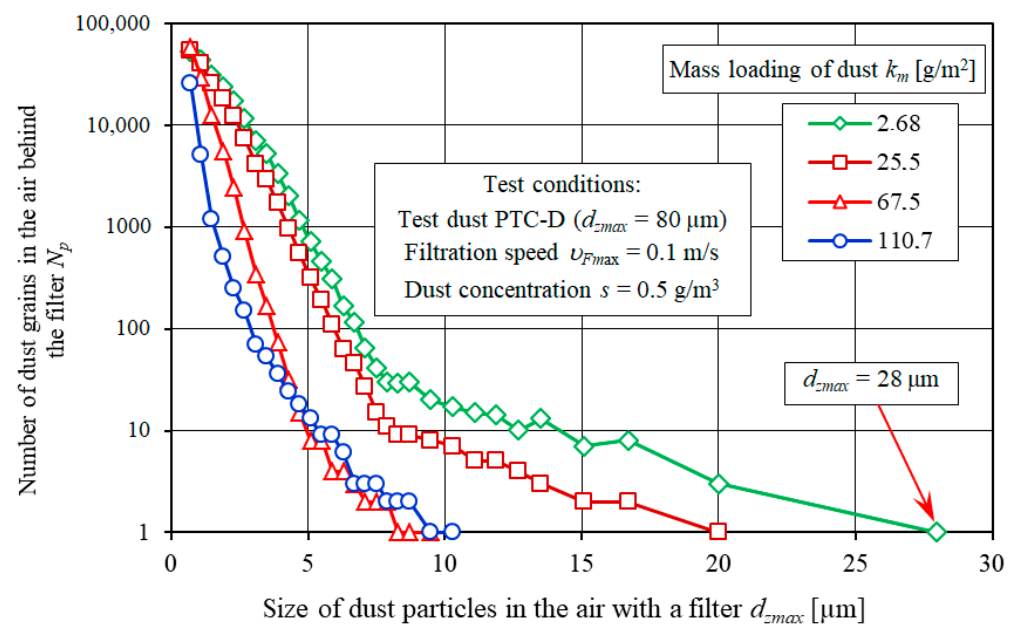

Figure 9. The number of dust particles in subsequent measuring intervals in the air downstream of the filter element A (cellulose).

Figure 10 shows the dust particle size distribution (test dust) upstream and downstream of the filter element A (cellulose). Dust with a particle size of up to $80 \mu \mathrm{m}$ is observed in the filter inlet air. A predominant particle size $\left(U_{p t}=16.2 \%\right)$ in the dust is $4 \mu \mathrm{m}$.

The size distribution of dust particles in the air downstream of the filter is completely different. The largest fraction of dust particles $U_{p}$ in the air downstream of the filter are the dust particles with size between $d_{z}=0.7$ and $1.1 \mu \mathrm{m}$ (Figure 10). For the filter element A (measurement no. 1- $k_{m}=2.68 \mathrm{~g} / \mathrm{m}^{2}$ ) 
the fraction is $U_{p 1}=26.3 \%$. For subsequent measurements, the fraction increases and for measurement no. $11\left(k_{m}=110.7 \mathrm{~g} / \mathrm{m}^{2}\right)$ is $U_{p 11}=77.5 \%$.

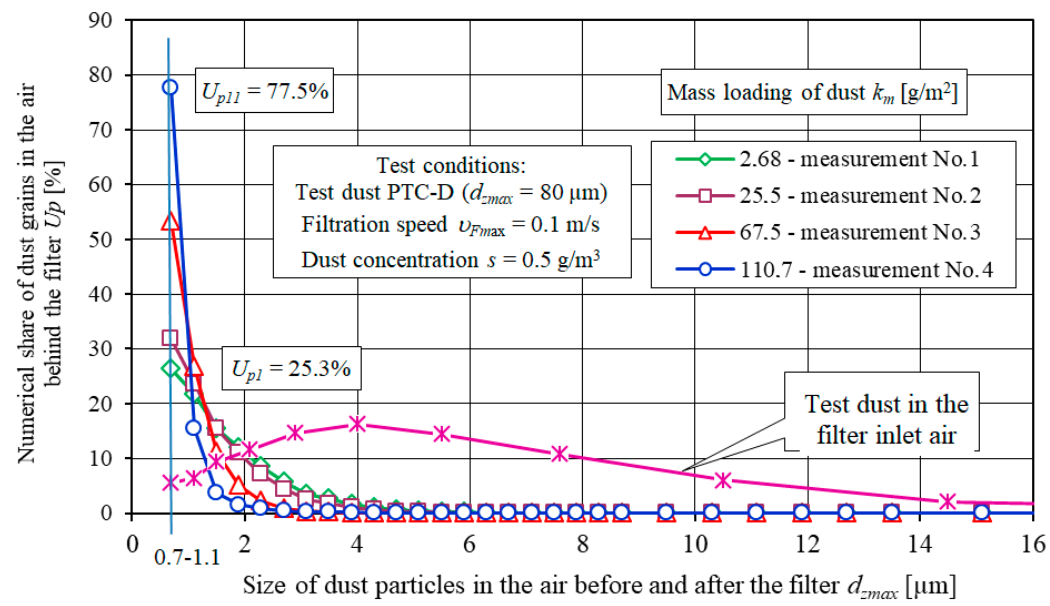

Figure 10. Share of dust particles in subsequent measuring intervals in the air upstream and downstream of the filter element A (cellulose).

The fraction of particles significantly decreases with an increase in dust particle size and the filtration process duration. The fraction of dust particles $d_{z}=2 \mu \mathrm{m}$ for measurement no. 1 is $U_{p 1}=11.6 \%$. For subsequent measurements, the fraction of particles $d_{z}=2 \mu \mathrm{m}$ increases and for measurement no. 11 is $U_{p 11}=1.5 \%$ (Figure 10 ). A similar change in the share of $U_{p}$ of dust grains in subsequent measurement intervals in the air behind the filter element occurs for other tested materials A, B, C, D and $\mathrm{E}$. There are differences in the values of the $U_{p}$ shares. The shorter the initial period of filtration, the greater the proportion of grains with dimensions $d_{z}=0.7-1.1 \mu \mathrm{m}$ (after measurement No. 1). In the air behind the E insert (polyester+PTFE membrane) for measurement no. $1\left(k_{m}=5.77 \mathrm{~g} / \mathrm{m}^{2}\right)$, the share of grains with dimensions $d_{z}=0.7-1.1 \mu \mathrm{m}$ has the value $U_{p 1}=67.9 \%$. For subsequent measurements, the share of these grains increases less intensively and does not exceed the value of $U_{p}=70 \%$.

Figures 11 and 12 show the detailed particle size distributions in the air downstream of the filter element $\mathrm{A}$ after reaching the mass loading of dust $k_{m A}=2.68 \mathrm{~g} / \mathrm{m}^{2}$ (measurement no. 1) and $k_{m D}=110.7 \mathrm{~g} / \mathrm{m}^{2}$ (measurement no. 11).

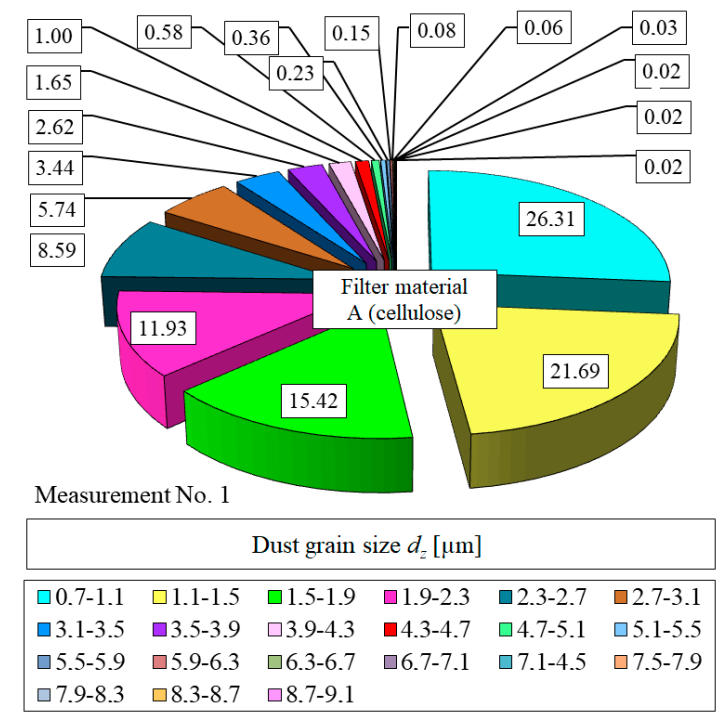

Figure 11. Particle size distribution in the air downstream of the filter element $\mathrm{A}$ after reaching the dust mass loading $k_{m A}=2.68 \mathrm{~g} / \mathrm{m}^{2}$ (measurement no. 1). 


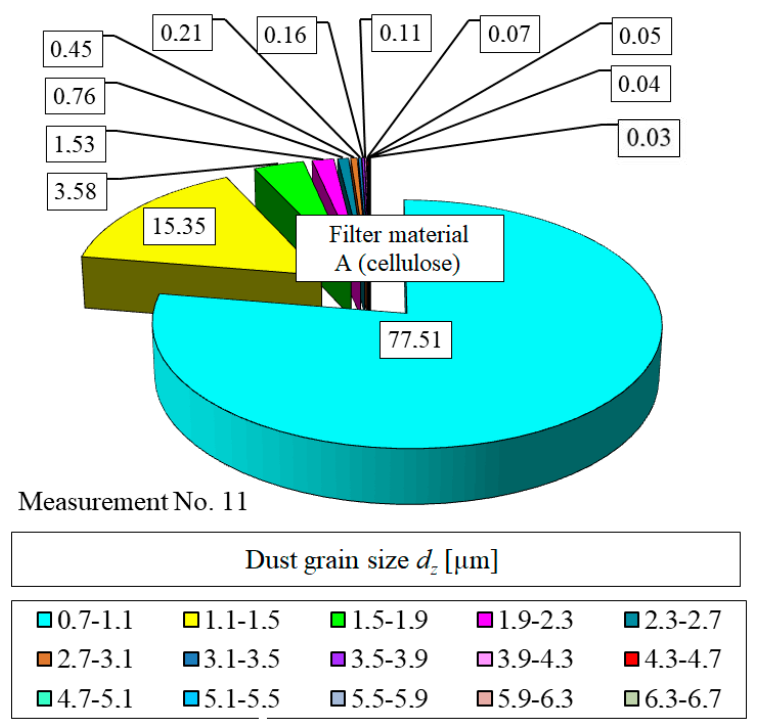

Figure 12. Particle size distribution in the air downstream of the filter element $A$ after reaching the dust mass loading $k_{m A}=110.7 \mathrm{~g} / \mathrm{m}^{2}$ (measurement no. 11).

Figure 13 shows the particle size distribution in the air downstream of the filter element $\mathrm{E}$ after reaching the mass loading of dust $k_{m A}=5.77 \mathrm{~g} / \mathrm{m}^{2}$ (measurement no. 1). The fraction of dust particles $d_{z}=0.7$ to $1.1 \mu \mathrm{m}$ is $U_{p 1}=67.9 \%$. It is similar to the value recorded for the filter element $\mathrm{A}$ at the end of the initial stage.

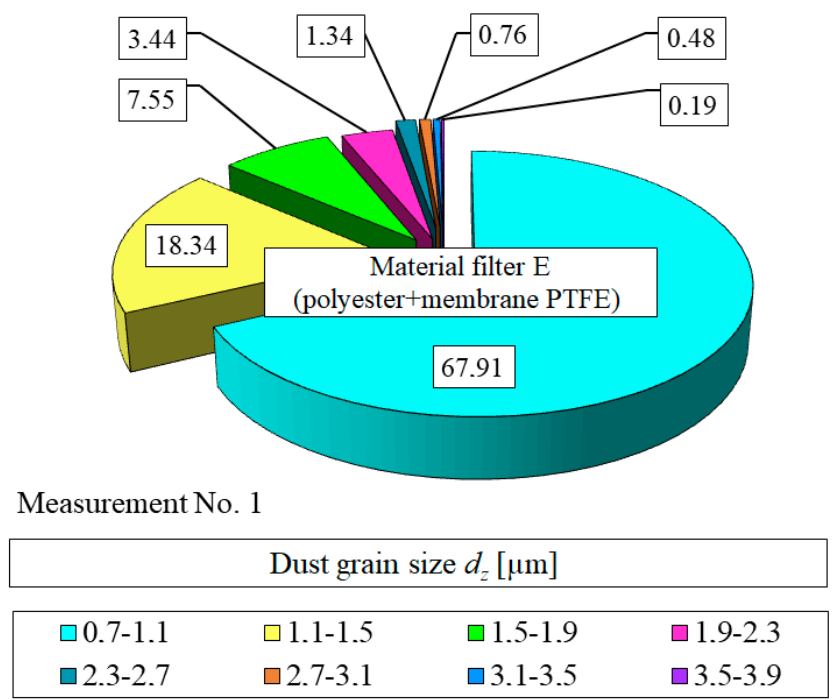

Figure 13. Particle size distribution in the air downstream of the filter element $\mathrm{E}$ after reaching the dust mass loading $k_{m A}=5.77 \mathrm{~g} / \mathrm{m}^{2}$ (measurement no. 1 ).

The accumulation of dust particles on the panel filter fibers changes the filter structure, reduces the surface area of the air stream flow around the fibers. The aerosol flow rate increases with an increase in pressure drop at the filter bed. An increase in pressure drop at the tested filter elements, despite similar testing conditions, differed in rate (Figure 14). The pressure drop of $\Delta p_{w}=3 \mathrm{kPa}$ is achieved by the filter elements after retaining different masses of dust. 


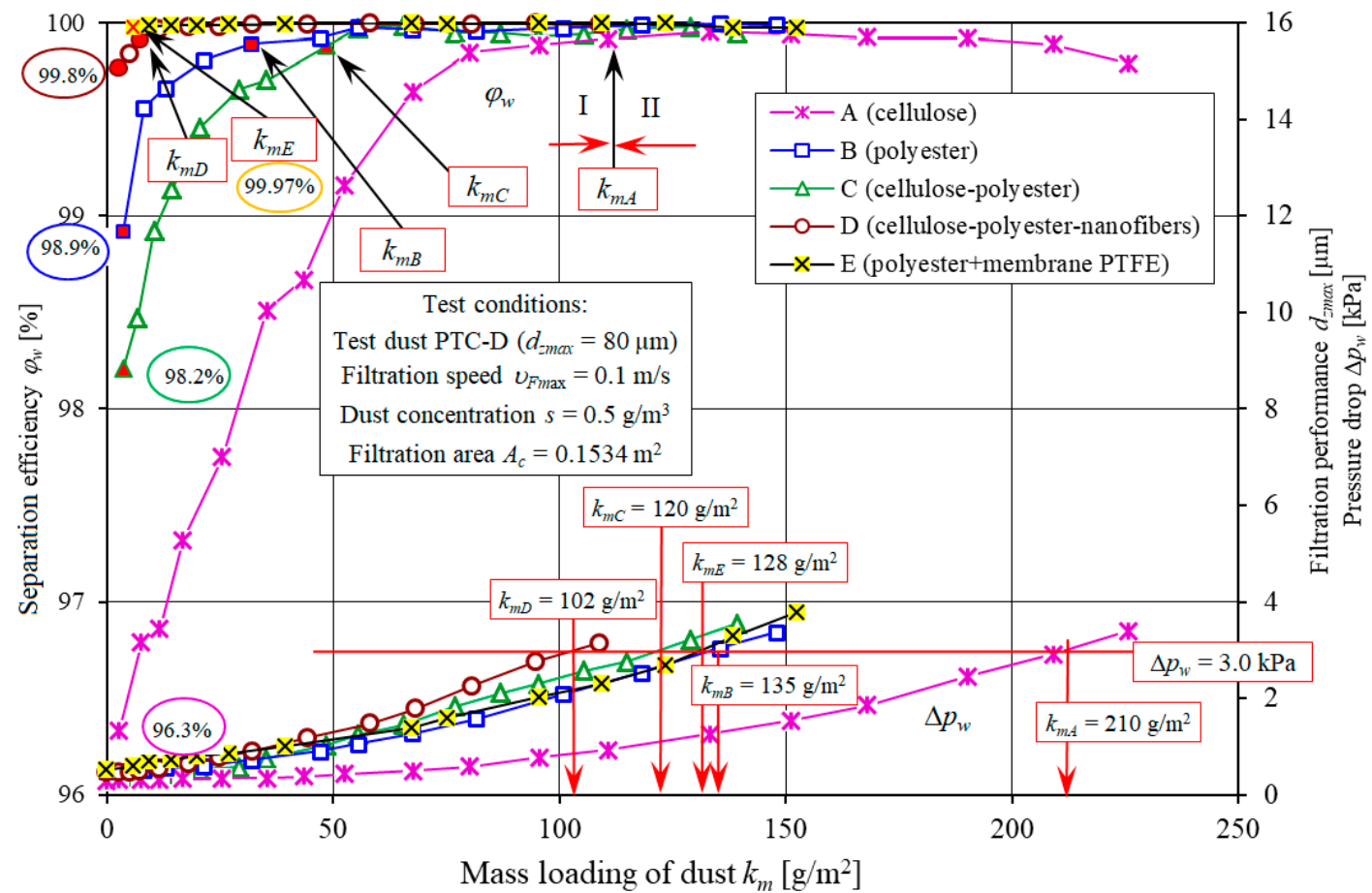

Figure 14. Separation efficiency $\varphi_{w}$ and pressure drop $\Delta p_{w}$ as a function of the mass loading of dust $k_{m}$ of the tested filter elements A, B, C, D and E.

Filter elements with a nanofiber layer are characterized by the lowest dust mass loading. It is determined by the surface filtration during which the dust particles are retained by the nanofiber layer before reaching the inside of the filter bed. At the point, the filter elements reach the pressure drop of $\Delta p_{\max }=3 \mathrm{kPa}$, they retain and accumulate different masses of dust. Filter elements $\mathrm{A}$ and $\mathrm{D}$ reach the dust mass loading of $k_{m A}=210 \mathrm{~g} / \mathrm{m}^{2}$ and $k_{m E}=108 \mathrm{~g} / \mathrm{m}^{2}$, respectively (Figure 12). Dust mass $\Delta k_{m}$ retained by the filter elements, from the point of achieving the separation efficiency of $\varphi_{w}=99.9 \%$ until the point of achieving the pressure drop of $\Delta p_{\max E}=3.0 \mathrm{kPa}$ is similar and is approx. $100 \mathrm{~g} / \mathrm{m}^{2}$ (Figure 12). It is determined by the duration of the initial period (I), which lasts from the moment the filter element achieves the separation efficiency of $\varphi_{w}=99.9 \%$. In this period, the air downstream of the filter contained large dust particles $\left(d_{z \max A}=28-15 \mu \mathrm{m}\right)$, affecting the engine durability. For filter element (A), the initial stage (I) is over $50 \%$ of its total service life, and significantly affects the abrasive wear of engine components. For filter elements (C, B and D), the period is shorter and is $40 \%, 22 \%$ and $6 \%$ of its total service life, respectively.

In the second (II) stage of the operation of the filter elements B, C, D, the separation efficiency is maintained at a stable level of $\varphi_{w}=99.9 \%$. For the filter element $\mathrm{A}$, a slight and systematic decrease in separation efficiency can be observed. In the last measurement, the separation efficiency was $\varphi_{w}=99.7 \%$. It may be due to the accumulation of a significant amount of dust in form of extensive tree-like dendrites [57]. The dust particles at the top of the dendritic structures are captured and transferred to the outlet side of the filter medium, and captured by the air stream from the engine cylinders. The decrease in the separation efficiency is related with the maximum dust particle size, reaching higher and higher values. For the last measurement, the value was $d_{z \max A}=16.7 \mu \mathrm{m}$. For the remaining filter elements, the maximum dust particle sizes $d_{z m a x}$ were stable at a significantly lower level. Downstream of filter element $D$ with a layer of nanofibers, the particle size was $d_{z \max D}=3.1$ to $5.1 \mu \mathrm{m}$. 
The filtration properties of the tested filter media were evaluated using a quality factor $q$ [31].

$$
q=\frac{-\ln \left(1-\frac{\varphi_{0}}{100}\right)}{\Delta p}\left(\frac{1}{\mathrm{kPa}}\right),
$$

where $\varphi_{0}$-initial efficiency of the filter bed [\%], $\Delta p$-pressure drop for nominal air volume flow rate $(\mathrm{kPa})$.

The calculation results shown in Figure 15 indicate that the highest quality factor was observed for specimen E (polyester+PTFE membrane) and specimen D: $q_{E}=15.4 \mathrm{kPa}^{-1}$ and $q_{D}=15.1 \mathrm{kPa}^{-1}$, respectively. Specimen $\mathrm{E}$ includes a membrane and specimen $\mathrm{D}$ includes a nanofiber layer. The specimens reach higher initial values of the separation efficiency: $\varphi_{\text {owE }}=99.97 \%$ and $\varphi_{\text {owD }}$ $=99.8 \%$, and filtration performance in the initial stage $d_{z \max E}$ below $15.8 \mu \mathrm{m}$ and below $d_{z \max D}$ $7.9 \mu \mathrm{m}$, respectively.

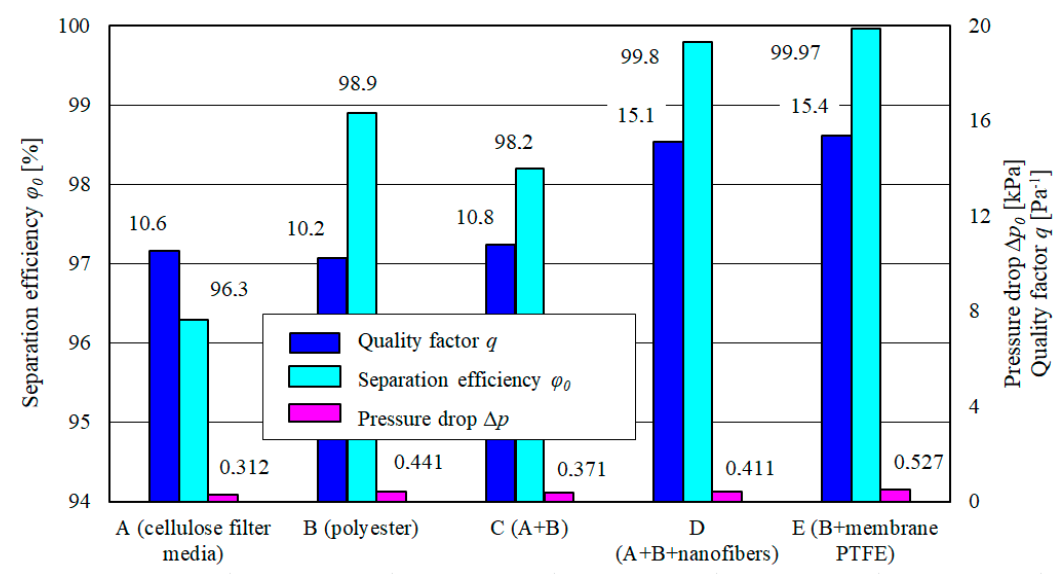

Figure 15. Separation efficiency of the tested filter media A, B, C, D and E.

A significantly lower value of the quality factor $q=10.6 \mathrm{kPa}^{-1}$ is achieved by specimen A (cellulose) as a result of lower initial separation efficiency $\varphi_{0 w A}=96.3 \%$. The separation efficiency is correlated with the filtration performance. Lower separation efficiency means not only lower mass of dust retained by the filter, but also larger dust particles in the air downstream of the filter, affecting the wear and durability of the internal combustion engine components.

\section{Conclusions}

1. A characteristic feature of the aerosol separation process in the filter media is an initial period characterized by low separation efficiency $\varphi_{w}$, filtration performance $d_{z m a x}$ and pressure drop $\Delta p_{w}$. The air downstream of the filter element may contain large dust particles $(28 \mu \mathrm{m})$, causing premature wear of engine components, in particular pistons, piston rings and cylinder sleeves, affecting its performance and durability.

2. The initial filtration period (time until the required filtration efficiency is reached- $\varphi=99.9 \%$ ) varies and depends on the filter medium used. A nanofiber layer or a PTFE membrane applied on the substrate made of conventional filter media (cellulose, polyester) significantly increase the separation efficiency $\varphi_{w}$ and filtration performance $d_{z \max }$. The initial filtration stage is several times shorter than for the filter element made of standard filter media only, which significantly reduces the wear of engine components.

3. With an increase in dust mass retained by the filter element (with an increase in dust mass loading $k_{m}$ ) the filtration performance and separation efficiency of the tested filters and pressure drop increase. Filter elements with a nanofiber layer and a PTFE layer show twice the rate of increase in pressure drop $\Delta p_{w}$ compared to the filter elements without those layers. The service life (vehicle 
mileage) until the permissible pressure drop is reached will be shorter, requiring more frequent filter element replacements, on one hand increasing the operating costs, on the other, due to higher filtration performance and reduced wear of engine components, extending the mean time to repair. The presented phenomenon of interrelationship increase in efficiency and accuracy of inlet air filtration with a significant increase in flow resistance applies to all filter materials with nanofiber layers. Data of bed with a PTFE layer are based only on the results obtained by the authors during their own research.

4. After reaching the permissible pressure drop $\Delta p_{w d o p}=3 \mathrm{kPa}$, the filter elements with a composite filter media retain $k_{m}=108-135 \mathrm{~g} / \mathrm{m}^{2}$ of dust. For the same pressure drop $\Delta p_{w d o p}$, filter element A (cellulose) achieves dust mass loading $k_{m}=209 \mathrm{~g} / \mathrm{m}^{2}$, almost $100 \%$ higher. The filter elements with a nanofiber layer or a PTFE membrane retain the dust at the surface, blocking the air flow through the layer, increasing the rate of an increase in pressure drop. It shows that in the filter beds with a nanofiber layer, a surface filtration process takes place, instead of a depth filtration process. Those type of filter media can be used in the filtration systems with pulse jet cleaning feature, significantly increasing the service life of the filter element.

5. The results of the experimental study partially fill the gap in the field of basic properties of materials used in the design and selection of panel filters for the inlet air of the internal combustion engine.

Filter material experimental research, which aims to determine filtration efficiency, accuracy and flow resistance changes, consist in performing a large number of measurements with test dust usage. Many conditions must be met. The filtration efficiency is most often determined by mass method, in measuring cycles which last few or several minutes. By weighting with a high-accuracy analytical scale, the sample weight is determined before and after the test (dust dosing) and then compared with dust weight delivered at that time. Dust dosing during the measurement should be even and ensure a fixed dust concentration value, which is a big problem in cases where there is a lack of an appropriate dosing device. The air stream flowing through the filter material sample should be constant, which ensures a constant, defined filtration speed. During the test, dust is retained on the sample, which increases its flow resistance, which causes a decrease in the air stream. Therefore, air flow should be constantly monitored and adjusted during the measurement. The test stand is also equipped with an absolute filter that stops contaminants that have passed through the tested sample. It thus protects air flow meter measuring element. However, it increases flow resistance in the measuring system. Type of test dust used is important during the tests. Test dusts differ in their chemical and particle size composition and should be selected depending on the type of the intended ground on which the vehicle will travel. The station is equipped with a particle counter that records dust grains number and size in the air behind the filter. It is important to maintain the isokinetic condition of the probe collecting the polluted air stream for analysis. Tests are time consuming and require many conditions to be met before and during the measurement. Appropriately trained personnel are essential. Experimental research is expensive, but it is the most reliable research method.

Author Contributions: Conceptualization, T.D.; methodology, T.D.; software, T.D. and S.D.D.; validation, T.D. and S.D.D.; formal analysis, T.D.; investigation, T.D. and S.D.D.; resources, T.D.; data curation, T.D.; writing-original draft preparation, T.D.; All authors have read and agreed to the published version of the manuscript.

Funding: This research was funded by part of the implementation of the university research grant No. UGB-22-756/2020, Faculty of Mechanical Engineering, Military University of Technology.

Conflicts of Interest: The authors declare no conflict of interest.

\section{References}

1. Chun, Y.; Kim, J.; Choi, J.C.; Boo, K.O.; Oh, S.N.; Lee, M. Characteristic number size distribution of aerosol during Asian dust period in Korea. Atmos. Environ. 2001, 35, 2715-2721. [CrossRef]

2. Baddocka, M.C.; Zobeck, T.M.; Van Pelt, R.S.; Fredrickson, E.L. Dust emissions from undisturbed and disturbed, crusted playa surfaces: Cattle trampling effects. Aeolian Res. 2011, 3, 31-41. [CrossRef] 
3. Young, J.M.; Kelly, T.M.; Vance, L. Determination of size fractions and concentrations of airborne particulate matter generated from construction and demolition waste processing facilities. Air Qual. Atmos. Health 2008, 1, 91-100. [CrossRef]

4. Chan, D.; Stachowiak, G.W. Review of automotive brake friction materials. Proc. Inst. Mech. Eng. Part D: J. Automob. Eng. 2004, 218, 953-966. [CrossRef]

5. Thorpe, A.; Harrison, R.H. Sources and properties of non-exhaust particulate matter from road traffic: A review. Sci. Total Environ. 2008, 400, 270-282. [CrossRef] [PubMed]

6. Grigoratos, T.; Martini, G. Non-Exhaust Traffic Related Emissions. Brake and Tyre Wear PM; JRC Science and Policy; Publications Office of the European Union: Luxembourg, 2014. [CrossRef]

7. Panko, J.; Kreider, M.; Unice, K. Review of Tire Wear Emissions A Review of Tire Emission Measurement Studies: Identification of Gaps and Future Needs. Non-Exhaust Emiss. 2018, 147-160. [CrossRef]

8. Kreider, M.L.; Panko, J.M.; McAtee, B.L.; Sweet, L.I.; Finley, B.L. Physical and chemical characterization of tire-related particles: Comparison of particles generated using different methodologies. Sci. Total Environ. 2010, 408, 652-659. [CrossRef]

9. Kupiainen, K.J.; Tervahattu, H.; Räisänen, M.; Mäkelä, T.; Aurela, M.; Hillamo, R. Size and composition of airborne particles from pavement wear, tires, and traction sanding. Environ. Sci. Technol. 2005, 39, 699-706. [CrossRef]

10. Cardozo, J.I.H.; Sánchez, D.F.P. An experimental and numerical study of air pollution near unpaved Roads. Air Qual. Atmos. Health 2019, 12, 471-489. [CrossRef]

11. Fujiwara, F.; Rebagliati, R.J.; Dawidowski, L.; Gómez, D.; Polla, G.; Pereyra, V.; Smichowski, P. Spatial and chemical patterns of size fractionated road dust collected in a megacitiy. Atmos. Environ. 2011, 45, 1497-1505. [CrossRef]

12. Smialek, J.L.; Archer, F.A.; Garlick, R.G. Turbine Airfoil Degradation in the Persian Gulf War. JOM 1994, 46, 39-40. [CrossRef]

13. Bojdo, N.; Filippone, A. Effect of desert particulate composition on helicopter engine degradation rate. In Proceedings of the 40th European Rotorcraft Forum, Southampton, UK, 2-5 September 2014.

14. Long, J.; Tang, M.; Sun, Z.; Liang, Y.; Hu, J. Dust Loading Performance of a Novel Submicro-Fiber Composite Filter Medium for Engine. Materials 2018, 11, 2038. [CrossRef]

15. Bojdo, N.; Filippone, A. A Simple Model to Assess the Role of Dust Composition and Size on Deposition in Rotorcraft Engines. Aerospace 2019, 6, 44. [CrossRef]

16. Nagy, J. Filtrowanie a żywotność silnika. Combust. Engines 1973, 3, 43-47.

17. Fitch, J. Clean Oil Reduces Engine Fuel Consumption. Pract. Oil Anal. 2002, 11. Available online: https://www.machinerylubrication.com/Read/401/oil-engine-fuel-consumption (accessed on 6 August 2020).

18. Diesel Engine Air Filtration. PALL Aerospace, Europa House, U.K.. 2004. Available online: http: //www.pall.com (accessed on 6 August 2020).

19. Barris, M.A. Total Filtration ${ }^{T M}$ : The Influence of Filter Selection on Engine Wear, Emissions, and PerformanceI; SAE Technical Paper 952557; SAE International: Toronto, ON, Canada, October 1995; pp. 16-19.

20. Bugli, N. Automotive Engine Air Cleaners-Performance Trends. SAE Tech. Paper 2001, 1, 1356.

21. Durst, M.; Klein, G.; Moser, N. Filtration in Fahrzeugen; Mann+Hummel GMBH: Ludwigsburg, Germany, 2005.

22. Truhan, J. Filter Performance as the Engine Sees It. Filtr. Sep. 1997, 34, 1019-1022.

23. Jaroszczyk, T.; Fallon, S.L.; Liu, Z.G.; Heckel, S.P. Development of a Method to Measure Engine Air Cleaner Fractional Efficiency. SAE Tech. Pap. Ser. 1999. [CrossRef]

24. Jaroszczyk, T.; Wake, J.; Connor, M.J. Factors Affecting the Performance of Engine Air Filters. J. Eng. Gas Turbines Power 1993, 115, 693-699. [CrossRef]

25. Kordas, $P$. The influence of the combustion engine work conditions on the cylinder wear in the stand test researches. Eksploat. I Niezawodn. Maint. Reliab. 2006, 4, 11-15.

26. Koszałka, G.; Suchecki, A. Changes in performance and wear of small diesel engine during durability test. Combust. Engines 2015, 162, 34-40.

27. Koszałka, G.; Suchecki, A. Changes in blow-by and compression pressure of a diesel engine during a bench durability test. Combust. Engines 2013, 154, 34-39.

28. Jaroszczyk, T.; Petrik, S.; Donahue, K. Recent development in heavy duty engine air filtration and the role of nanofiber filter media. J. KONES Powertrain Transp. 2009, 16, 207-216. 
29. Tiana, X.; Ou, Q.; Liu, J.; Liang, Y.; Pu, D.Y.H. Particle loading characteristics of a two-stage filtration system. Sep. Purif. Technol. 2019, 215, 351-359. [CrossRef]

30. Rieger, M.; Hettkamp, P.; Löhl, T.; Madeira, P.M.P. Effcient Engine Air Filter for Tight Installation Spaces. ATZ 2019, 12, 56-59.

31. Braun, R.; Sauter, H.; Seggern, J.; Enderich, A. Moderne Filtermedien in Labor und Praxis. MTZ 2006, 12, 947-980.

32. Dziubak, T. Performance characteristics of air intake pleated panel filters for internal combustion engines in a two-stage configuration. Aerosol Sci. Technol. 2018, 52, 1293-1307. [CrossRef]

33. Bojdo, N.; Filippone, A. A Comparative Study of Helicopter Engine Air Particle Separation Technologies. In Proceedings of the European Rotorcraft Forum, Amsterdam, The Netherlands, 2-6 September 2012.

34. Hakobyan, N.A. Introduction to Basics of Submicron Aerosol Particles Filtration Theory via Ultrafine Fiber Media. Armen. J. Phys. 2015, 8, 140-151.

35. Kanaoka, C. Fine Particle Filtration Technology Using Fiber as Dust Collection Medium. KONA Powder Part. J. 2019, 36, 88-113. [CrossRef]

36. Jaroszczyk, T.; Pardue, B.A.; Heckel, S.P.; Kallsen, K.J. Engine air cleaner filtration performance-theoretical and Experimental background of testing. In Proceedings of the AFS Fourteenth Annual Technical Conference and Exposition, Tampa, FL, USA, 1 May 2001.

37. Yuan, W.; Fang, G.; Li, Z.; Chen, Y.; Tang, Y. Using Electrospinning-Based Carbon Nanofiber Webs for Methanol Crossover Control in Passive Direct Methanol Fuel Cells. Materials 2018, 11, 71. [CrossRef]

38. Haider, A.; Haider, S.; Kang, I.K. A comprehensive review summarizing the effect of electrospinning parameters and potential applications of nanofibers in biomedical and biotechnology. Arab. J. Chem. 2018, 11, 1165-1188. [CrossRef]

39. Wei, L.; Qin, X. Nanofiber bundles and nanofiber yarn device and their mechanical properties: A review. Text. Res. J. 2016, 86, 1885-1898. [CrossRef]

40. Grafe, T.H.; Graham, K.M. Nanofiber Webs from Electrospinning. Nonwovens in Filtration. In Proceedings of the 5th International Conference, Stuttgart, Germany, 1-5 March 2003; Available online: https://www. jusdust.com/Product_Literature/cart_3.pdf (accessed on 6 August 2020).

41. Grafe, T.; Gogins, M.; Barris, M.; Schaefer, J.; Canepa, R. Nanofibers in Filtration Applications in Transportation. In Proceedings of the Filtration 2001 International Conference and Exposition, Chicago, IL, USA, 3-5 December 2001.

42. Khajavi, R.; Abbasipour, M. Electrospinning as a versatile method for fabricating coreshell, hollow and porous nanofibers. Scientia Iranica. Trans. F Nanotechnol. 2012, 19, 2029-2034.

43. Lim, C.T. Nanofiber technology: Current status and emerging developments. Prog. Polym. Sci. 2017, 70, 1-17. [CrossRef]

44. Wang, J.; Kim, S.C.; Pui, D.Y.H. Figure of Merit of Composite Filters with Micrometer and Nanometer Fibers. Aerosol Sci. Technol. 2008, 42, 722-728. [CrossRef]

45. Lo, L.M.; Chen, D.-R.; Pui, D.Y.H. Experimental study of pleated fabric cartridges in a pulse-jet cleaned dust collector. Powder Technol. 2010, 197, 141-149. [CrossRef]

46. Long, J.; Tang, M.; Liang, Y.; Hu, J. Preparation of fibrillated cellulose nanofiber from lyocell fiber and its application in air filtration. Materials 2018, 11, 1313. [CrossRef]

47. Podgórski, A.; Bałazy, A.; Gradon, L. Application of nanofibers to improve the filtration efficiency of the most penetrating aerosol particles in fibrous filters. Chem. Eng. Sci. 2006, 61, 6804-6815. [CrossRef]

48. Wang, Q.; Yildiz, O.; Li, A.; Aly, K.; Qiu, Y.; Jiang, Q.; Pui, D.Y.H.; Chen, S.C.; Bradford, P.D. High Temperature Carbon Nanotube-Nanofiber Hybrid Filters. Sep. Purif. Technol. 2020, 236, 116255. [CrossRef]

49. Pei, C.; Oua, Q.; Yub, T.; Pui, D.Y.H. Loading characteristics of nanofiber coated air intake filter media by potassium chloride, ammonium sulfate, and ammonium nitrate fine particles and the comparison with conventional cellulose filter media. Sep. Purif. Technol. 2019, 228, 115734. [CrossRef]

50. Liu, J.; Pui, D.Y.H.; Wang, J. Removal of airborne nanoparticles by membrane coated filters. Sci. Total Environ. 2011, 409, 4868-4874. [CrossRef] [PubMed]

51. Liu, X.; Shen, H.; Nie, X. Study on the Filtration Performance of the Baghouse Filters for Ultra-Low Emission as a Function of Filter Pore Size and Fiber Diameter. Int. J. Environ. Res. Public Health 2019, 16, 247. [CrossRef] [PubMed] 
52. Dziubak, T. Properties of material with nanofiber layer used for filtering the inlet air of internal combustion engines. Combust. Engines 2019, 177, 66-75. [CrossRef]

53. Dziubak, T.; Szwedkowicz, S. Operating properties of non-woven fabric panel filters for internal combustion engine inlet air in single and two-stage filtration systems. Eksploat. I Niezawodn. Maint. Reliab. 2015, 17, 519-527. [CrossRef]

54. Erdmannsdörfer, H. Lesttingmoglichkeiten von Papierfiltern zur Reinigung der Ansaugluft von Diselmotoren. MTZ 1971, 32, 123-131.

55. Taufkirch, G.; Mayr, G. Papierluftfilter für Motoren in Nutzfahrzeugen. MTZ 1984, 45, 95-105.

56. Dziubak, T.; Bakała, L. Experimental research of the material filtration characteristics with nanofibers addition. J. KONES Powertrain Transp. 2018, 25, 83-94.

57. Kasper, G.; Stefan, S.; Meyer, J. Structure and density of deposits formed on filter fibers by inertial particle deposition and bounce. J. Aerosol Sci. 2010, 41, 1167-1182. [CrossRef]

(C) 2020 by the authors. Licensee MDPI, Basel, Switzerland. This article is an open access article distributed under the terms and conditions of the Creative Commons Attribution (CC BY) license (http://creativecommons.org/licenses/by/4.0/). 